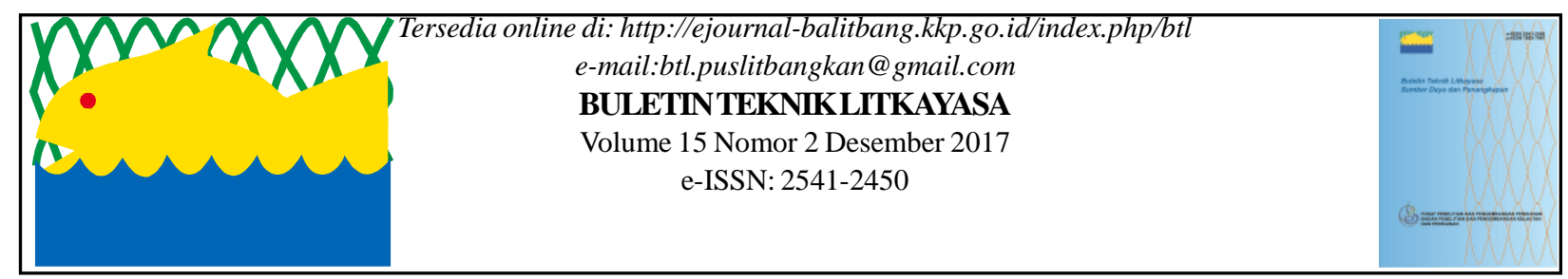

\title{
UJI OPERASIONAL ARTIFISIAL HABITAT DI PERAIRAN UMUM DARATAN DI GAJAH MUNGKUR
}

\author{
Agus Riyanto, Amani Edi S dan Agus Sudarto \\ Teknisi Litkayasa pada Balai Besar Penangkapan Ikan Semarang \\ Teregistrasi I tanggal: 30 November 2017; Diterima setelah perbaikan tanggal: 08 Desember 2017; \\ Disetujui terbit tanggal: 13 Desember 2017
}

\section{PENDAHULUAN}

Waduk Gajah Mungkur seluas 8.800 hektar, terbentuk karena pembendungan sungai bengawan Solo. Terletak di Kabupaten Wonogiri Jawa Tengah kurang lebih berjarak $3 \mathrm{Km}$ sebelah selatan dari pusat Kota Wonogiri. Waduk Gajah Mungkur mempunyai kedalaman maksimal 28 meter dan kedalaman rata rata 9 meter pada saat musim penghujan dan pada saat musim kemarau dibeberapa tempat mempunyai kedalan berkisar antara 2-20 meter. Waduk Gajah Mungkur merupakan waduk serba guna yang dibangun tahun 1984 yang dimanfaatkan untuk irigasi persawahan, pembangkit tenaga listrik, sumber air minum, parawisata, perikanan budidaya maupun tangkap (Direktorat Pengelolaan Bengawan Solo, 2003). Waduk Gajah Mungkur mempunyai laju sedimentasi per tahun 7.03 juta meter kubik. Kawasan jalur hijau seluas 1.653 ha pada elevasi $138-140 \mathrm{~m}$, sedangkan kondisi air waduk paling tinggi saat banjir adalah $138.2 \mathrm{~m}$ sehingga kawasan jalur hijau tidak akan tergenang air.

Perikanan Tangkap mempunyai arti penting bagi perekonomian masyarakat sekitar waduk. Jumlah kelompok nelayan di Waduk Gajah Mungkur 48 kelompok dengan jumlah anggota sebanyak 1.266 orang. Produksi perikanan tangkap sebesar 960 ton per tahun yang didominasi oleh ikan nila (Oreochromis niloticus), Patin (Pangasius sp) Tawes (Barbodes gonionotus) (Dinas Kehewanan dan Perikanan Wonogiri).

Salah satu upaya Pemerintah daerah untuk meningkatkan produksi perikanan tangkap yaitu dengan penebaran ikan (restoking). Selain upaya restoking pengkayaan sumber daya ikan perairan umum juga dapat dilakukan dengan pembuatan Artifisial Habitat.

Artifisial Habitat yang dimaksud adalah suatu bangunan terbuat dari plastk dengan konstruksi kusus bertujuan sebagai tempat yang cocok untuk ikan berkumpul, berlindung, mencari makan dan berkembang biak/berpijah.

Balai Besar Penangkapan Ikan Semarang selaku Unit Pelaksana Teknis (UPT) Direktorat Jenderal Perikanan Tangkap, Kementerian Kelautan dan Perikanan, tahun 2016 melakukan Uji Operasional Artifisial Habitat di Perairan Umum untuk Pengkayaan SDI Melalui Rekayasa Lingkungan sehingga diharapkan dapat menunjang kinerja dalam rangka pengelolaan sumberdaya ikan serta penyebarluasan teknologi pengelolaan sumberdaya ikan yang bertanggung jawab.

Sebagai tindak lanjut kegiatan Uji Operasional Artifisial Habitat ini dilakukan Monitoring Evaluasi (Monev) untuk mendapatkan data dan informasi hasil kegiatan baik aspek teknis maupun administratifnya.

\section{Tujuan}

1. Menenggelamkan benda uji ke lokasi reservat

2. Melengkapi benda uji dengan batas yang terbuat dari pralon diisi polyuretan, batas terbuat dari bambu. Batas ini juga berfungsi sebagai tempat bergantungnya Artifisial Habitat Type III.

3. Melakukan monev manfaat benda uji.

\section{Sasaran}

1. Penyempurnaan tata letak jumlah benda uji dan perluasan area artifisial habitat.

2. Bukti keberhasilan artifisial habitat yang dipasang, ditenggelamkan adalah artifisial habitat tersebut dihuni oleh beberapa jenis ikan dengan berbagai ukuran.

3. Uji Operasional Artifisial Habitat di Perairan Umum untuk Pengkayaan Sumber Daya Ikan Melalui Rekayasa Lingkungan dan menerapkan pengelolaan sumberdaya perikanan yang bertanggungjawab 


\section{POKOK BAHASAN}

Waktu dan Lokasi

Penenggelaman Artifisial Habitat di Gajah Mungkur dipasang didaerah reservaat Kelurahan Wonoharjo Desa Puthuk, Kabupaten, Wonogiri 16-25 Juni 2016
(Gambar 1). Agar terlindung dari upaya penangkapan oleh nelayan. Daerah reservaat di Gajah Mungkur mencakup luasan 48 Ha lokasi ini termasuk Desa Putuk dengan kedalaman perairan apabila kemarau 1.5 sampai dengan 2 meter, apabila penghujan 5 sampai dengan 6 meter. Dasar perairan Berlumpur.

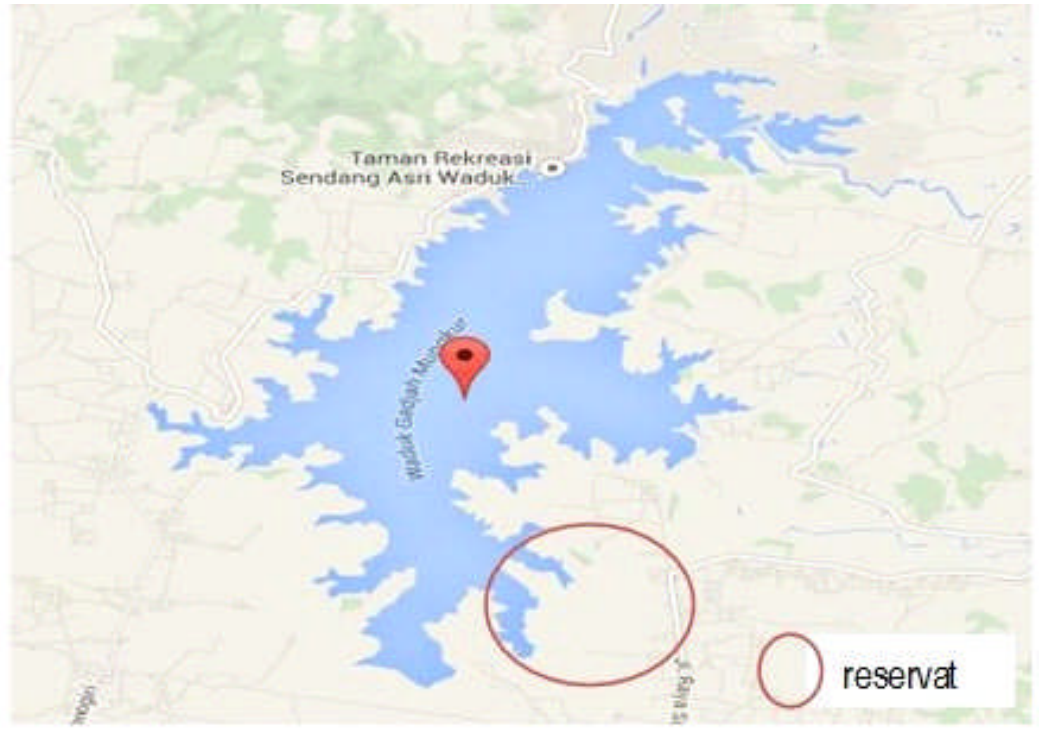

Gambar 1. Lokasi Penenggelaman Artifical Habitat.

\section{Bahan dan Peralatan}

Peralatan / instrumen yang dipergunakan untuk pengukuran adalah:

1. Meteran/mistar untuk melakukan pengukuran komponen artifisial habitat,

2. Timbangan untuk melakukan pengukuran berat komponen artifisial habitat
3. Alat tulis untuk mencatat data

4. Kamera, mendokumentasikan ikan hasil pengukuran artifisial habitat

Bahan yang dibutuhkan untuk pembuatan Artifisial Habitat (Tabel 1-3) dan desainnya (Gambar 2).

Tabel 1a. Bahan komponen arifisial habitat model dasar

\begin{tabular}{|c|c|c|c|c|}
\hline No & Komponen & Bahan & Ukuran & Berat \\
\hline 1. & Pelampung tanda & Pelampung botol & $\varnothing 3$ in & \\
\hline 2. & Partisi & Partisi vertikal & $35 \times 40 \mathrm{~cm}$ & \\
\hline 3. & Atraktor & $\begin{array}{l}\text { Partisi Horizontal } \\
\text { Genting } \\
\text { Plastic band }\end{array}$ & $\begin{array}{l}35 \times 35 \mathrm{~cm} \\
30 \times 25 \mathrm{~cm} \\
0.5 \text { gulung }\end{array}$ & \\
\hline 4. & Tali temali & $\begin{array}{l}\text { ljuk } \\
\text { Kelobot jagung } \\
\text { PA monofilamen } \\
\text { PE } \\
\text { PE }\end{array}$ & $\begin{array}{l}- \\
\text { no. } 400 \\
\varnothing 3 \mathrm{~mm}, 30 \mathrm{~m} \\
\varnothing 10 \mathrm{~mm}, 9 \mathrm{~m}\end{array}$ & $\begin{array}{l}2 \mathrm{~kg} \\
1 \mathrm{~kg} \\
2 \text { roll }\end{array}$ \\
\hline 6. & Tiang pancang & Bamboo & $\varnothing 10 \mathrm{~cm}, 8 \mathrm{~m}$ & \\
\hline
\end{tabular}


Tabel 1b. Komponen bahan artifisial habitat dasar perairan

\begin{tabular}{|c|c|c|c|c|c|}
\hline No & Komponen & Bahan & Ukuran & Kebutuhan & Jumlah \\
\hline 1. & Pelampung tanda & Pelampung botol & $\varnothing 10 \mathrm{~cm}$ & $\begin{array}{l}2 \text { buah/ } \\
\text { modul }\end{array}$ & \\
\hline 2. & Partisi & 3 tingkat & $105 \times 105 \times 120 \mathrm{~cm}$ & $\begin{array}{l}8 \text { partisi vertical } \\
2 \text { partisi horizontal }\end{array}$ & - \\
\hline 3. & Atraktor & $\begin{array}{l}\text { Plastic band } \\
\text { ljuk } \\
\text { Kkelobot jagung }\end{array}$ & $\begin{array}{l}2 \times 70 \mathrm{~cm} \\
- \\
-\end{array}$ & & $\begin{array}{l}25.2 \\
1 \mathrm{~kg} \\
2 \mathrm{~kg}\end{array}$ \\
\hline 4. & Tali temali & $\begin{array}{l}\text { PA monofilamen } \\
\text { PE } \\
\text { PE }\end{array}$ & $\begin{array}{l}\mathrm{no} .400 \\
\varnothing 3 \mathrm{~mm} \\
\varnothing 10 \mathrm{~mm}\end{array}$ & & $\begin{array}{l}2 \text { roll } \\
25 \mathrm{~m} \\
10 \mathrm{~m}\end{array}$ \\
\hline 5. & Tiang pancang & Bambu & $\varnothing 10 \mathrm{~cm}$ & 28 meter & $\begin{array}{l}4 \text { batang @ } 7 \\
\text { m }\end{array}$ \\
\hline
\end{tabular}

Tabel.2a. Bahan komponen artifisial habitat model menggantung paralon

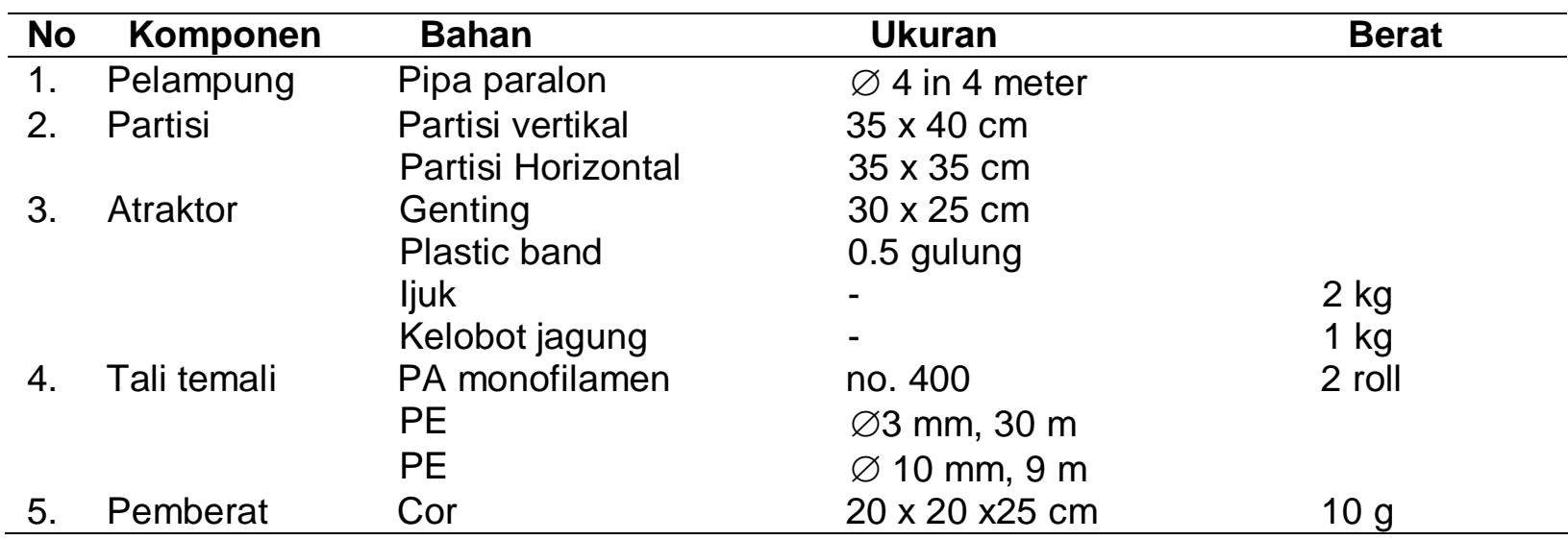

Tabel 2b. Komponen, bahan artifisial habitat menggantung paralon

\begin{tabular}{|c|c|c|c|c|}
\hline No Komponen & Bahan & Ukuran & Kebutuhan & Jumlah \\
\hline 1. Pelampung & Pipa paralon & $2 \times 2 \mathrm{~m}$ & 12 meter & 3 batang@4 m \\
\hline \multirow[t]{2}{*}{ 2. Partisi } & 2 tingkat & $\begin{array}{r}35 \times 35 \\
\times 80 \mathrm{~cm}\end{array}$ & 8 partisi vertical & 5 buah \\
\hline & 3 tingkat & $35 \times 35 \times 120 \mathrm{~cm}$ & $\begin{array}{l}3 \text { partisi horizontal } \\
12 \text { partisi vertical } \\
4 \text { partisi horizontal }\end{array}$ & 4 buah \\
\hline \multirow[t]{3}{*}{ 3. Atraktor } & Genting & $30 \times 25 \mathrm{~cm}$ & & 9 buah \\
\hline & $\begin{array}{l}\text { Plastic band } \\
\text { liuk }\end{array}$ & $2 \mathrm{~cm} \times 70 \mathrm{~cm}$ & & $\begin{array}{l}61.6 \mathrm{~m} \\
1 \mathrm{~kg}\end{array}$ \\
\hline & Kelobot jagung & - & & $1 \mathrm{~kg}$ \\
\hline \multirow[t]{3}{*}{ 4. Tali temali } & $\begin{array}{l}\text { PA } \\
\text { monofilamen }\end{array}$ & no. 400 & & 2 roll \\
\hline & PE & $\varnothing 3 \mathrm{~mm}$ & & $30 \mathrm{~m}$ \\
\hline & PE & $\varnothing 10 \mathrm{~mm}$ & & $9 \mathrm{~m}$ \\
\hline 5. Pemberat & Cor & $20 \times 20 \times 25 \mathrm{~cm}$ & & $10 \mathrm{~g}$ \\
\hline
\end{tabular}


Tabel 3. Kebutuhan bahan artifisial habitat menggantung bamboo

\begin{tabular}{lllll}
\hline No Komponen & Bahan & Ukuran & Kebutuhan & Jumlah \\
\hline 1. Pelampung & Bamboo & $\varnothing 10 \mathrm{~cm}$ & $288 \mathrm{~m}$ & 8 batang@6। \\
& & $24 \times 24 \mathrm{~m}$ & & \\
2. Partisi & 3 tingkat & $5 \times 35 \times 120 \mathrm{~cm}$ & 12 partisi vertical & 20 buah \\
& & & 4 partisi horizontal & \\
3. Atraktor & Genting & $30 \times 25 \mathrm{~cm}$ & & $20 \mathrm{buah}$ \\
& Plastic band & $2 \times 70 \mathrm{~cm}$ & $168 \mathrm{~m}$ \\
& ljuk & - & & $4 \mathrm{~kg}$ \\
& Kelobot jagung & - & & $2 \mathrm{~kg}$ \\
4. Tali temali & PA monofilamen & no.400 & & $280 \mathrm{~m}$ \\
& PE & $\varnothing 3 \mathrm{~mm}$ & $100 \mathrm{~m}$ \\
& PE & $\varnothing 10 \mathrm{~mm}$ & & 8 batang@7n \\
5. Tiang & Bambu & $\varnothing 10 \mathrm{~cm}$ & 56 meter & \\
\hline
\end{tabular}

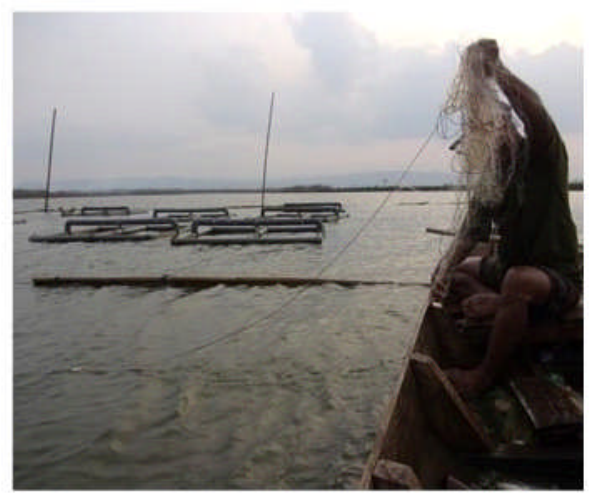

Gambar 2a. Artifisial Habitat di Waduk Gajah Mungkur

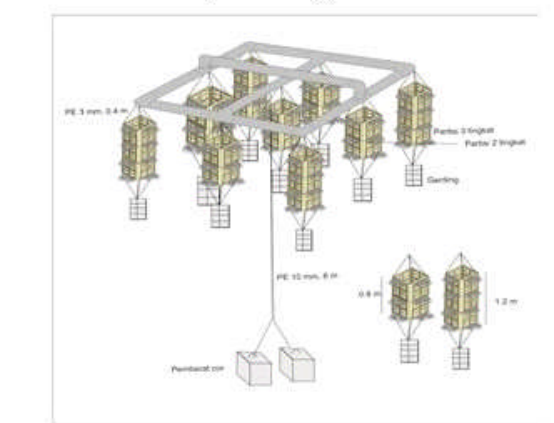

Gambar 2c. Desain Artifisial Habitat bagian Permukaan

\section{Metode}

Metoda yang digunakan dalam pelaksanaan kegiatan Uji Operasional Artifisial Habitat di Perairan Umum Daratan di Gajah Mungkur adalah sebagai berikut:

1. Data primer yang ingin diperoleh dari kegiatan ini adalah data lokasi reservat tempat dipasang melalui pengamatan / wawancara / kuesioner.

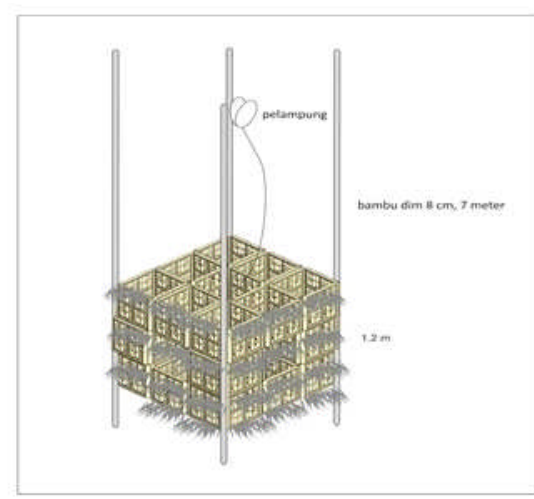

Gambar 2b. Desain Artifisial Habitat bagian Dasar

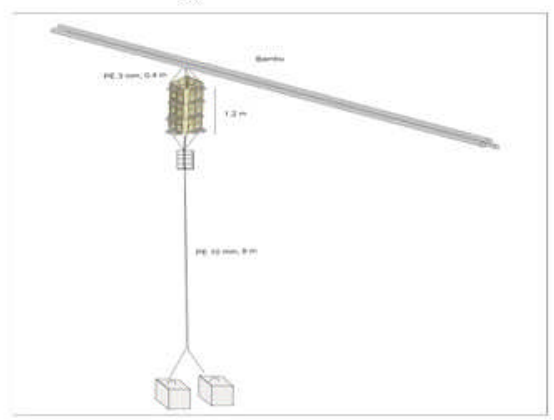

Gambar 2d. Desain Artifisial Habitat dalam satua kesatuan alat

2. Data hasil identifikasi jenis ikan, ukuran, jumlah ikan di artifisial habitat, keberdaan telur ikan yang menempel di atraktor.

3. Pengujian ini dilakukan untuk mendapatkan data apakah bentuk artifisial habitat berpengaruh disukai ikan yang menghuninya, jenis atraktor terhadap ketertarikan ikan untuk menempelkan telurnya. 
Deskripsi Reservat, Lokasi Penenggelaman Artificial Habitat

1) Kedalaman air 9 meter yang terjadi pada JanuariMaret.

2) Sedangkan pada saat surut terendah (puncak musim kemarau) kedalaman air hanya sekitar 1.52 meter yang terjadi pada bulan Agustusseptember.

3) Kecerahan air pada zona konservasi (perairan dangkal dekat dengan oulet dan inlet lebih rendah daripada perairan yang dalam, hanya mencapai $7-54 \mathrm{~cm}$.

4) Di zona konservasi Wiroko pada musim penghujan merupakan puncak musim memijah bagi ikan patin dan ikan lainnya, sehingga ikan tangkapan disekitar zona konservasi pada saat musim penghujan sangat melimpah.

5) Sedangkan pada saat puncak musim kemarau merupakan musim paceklik, dimana hasil tangkapan menurun. Biasanya nelayan beralih menjadi petani di pinggiran waduk yang surut.

6) Jarak pasang tertinggi hingga surut terendah mencapai 60 meter dengan selisih kedalaman mencapai 6 meter.

7) Ketebalan lumpur didasar perairan mencapai 1-2 meter.

\section{Karakteristik Kualitas Perairan}

a. Suhu perairan Waduk Gajah Mungkur berkisar antara 25, 5-35 p C. Suhu dapat mempengaruhi metabolisme dan respirasi ikan, peningkatan suhu akan mempengaruhi konsumsi oksigen ikan. Bila suhu perairan tinggi dan kadar oksigen rendah makan akan menimbulkan permasalahan bagi ikan terutama ikan pada KJA yang terkurung, karena peningkatan konsumsi oksigen oleh ikan tidak diimbangi dengan ketersediaan oksigen di perairan.

b. Kecerahan perairan Waduk Gajah Mungkur rendah, berkisar antara 7-137 $\mathrm{cm}$. Nilai kecerahan pada perairan dangkal lebih rendah dari perairan dalam. Pada musim penghujan banyak materi sedimen terbawa air ke waduk, sehingga perairan menjadi keruh, nilai kecerahan rendah dan kekeruhan tinggi.

Nilai kekeruhan Waduk Gajah Mungkur berkisar antara 1,5 NTU - 689 NTU. Hal ini disebabkan banyaknya bahan suspensi berupa koloid dan partikel halus. Nilai kekeruhan juga menunjukkan banyaknya partikel anorganik dari hasil erosi dan bahan organic yang terlarut berasal dari limbah budidaya ikan maupun limbah rumah tangga.

c. Total Suspended Solid (TSS), Waduk Gajah Mungkur cenderung lebih tinggi saat musim penghujan dari pada musim kemarau. Hal tersebut disebabkan karena saat musim penghujan banyak materi dari hasil erosi.

Nilai TSS pada stasiun dekat Keduang paling tinggi bila dibandingkan yang lain, hal tersebut bias dijadikan indikasi bahwa sungai Kedaung banyak membawa materi dari hasil erosi ke Waduk Gajah Mungkur.

d. Total Dissolved Solid (TDS), adalah bahan terlarut yang berupa senyawa kimia dan bahan lainnya yang tidak tersaring oleh kertas saring berdiameter $0,45 \mu \mathrm{m}$. Nilai TDS saat musim kemarau cenderung lebih tinggi daripada musim penghujan, karena musim kemarau volume airnya kecil.

e. Dissolved Oxygen (DO), kandungan oksigen pada lapisan permukaan sampai kedalaman 3 meter nilainya lebih besar $3 \mathrm{mg} / \mathrm{L}$. Dengan demikian kandungan oksigen di Waduk sampai kedalaman 3 meter masih bisa memenuhi syarat minimal kebutuhan ikan. Kandungan oksigen terlarut minimal $3 \mathrm{mg} / \mathrm{L}$ maka ikan dapat tumbuh, kurang dari $3 \mathrm{mg} / \mathrm{L}$ hingga $2 \mathrm{mg} / \mathrm{L}$ ikan masih dapat bertahan hidup namun pertumbuhannya terganggu, sedangkan bila kurang $2 \mathrm{mg} / \mathrm{L}$ dapat menyebabkan kematian bagi ikan. Nilai oksigen di dasar perairan terendahadalah di daerah KJA, disebabkan bahan organic dari sisa pakan ikan maupun kotoran ikan yang membusuk di dasar perairan akan mereduksi oksigen sehingga oksigen di dasar perairan KJA lebih rendah dari daerah lain.

f. Karbon Dioksida (CO2), kadar karbon dioksida pada kedalaman kurang dari 3 meter nilainya kurang dari $10 \mathrm{mg} / \mathrm{L}$. Keberadaan karbondioksida sangat diperlukan untuk fitoplankton dalam fotosintesis. Namun dalam jumlah banyak akan mengakibatkan racun bagi ikan. Karena pada saat karbon dioksida banyak maka nilai oksigen mengecil. Jika terjadi demikian maka karbon diokasida dapat menghambat pernapasan organisme air, dan pada demikian maka ikan akan keracunan karbon dioksida, daya serap oksigen oleh hemoglobin akan menurun.

g. Alkalinitas dan $\mathrm{pH}$, Waduk Gajah Mungkur memiliki pH antara 6,5-9, kisaran nilai alkalinitas antara $30-89 \mathrm{mg} / \mathrm{L}$. hal tersebut terjadi karena posisi waduk yang dikelilingi oleh daerah perbukitan kapur, batu gamping yang bersifat basah. Nilai alkalinitas yang melebihi $40 \mathrm{mg} / \mathrm{L}$ termasuk perairan sadah.

\section{Tingkat Kesuburan Perairan}

a. Berdasarkan kandungan fosfor

Pada kedalaman 0 - $5 \mathrm{~m}$ berkisar antara 5,2 $115(\mu \mathrm{g} / \mathrm{L})$ dengan nilai rata-rata $39,8(\mu \mathrm{g} / \mathrm{L})$. 
Perairan Gajah Mungkur dilihat kandungan fosfot termasuk dalam kategori perairan eutrofik (kesuburan tinggi). Kadar fosfot yang tinggi di perairan merupakan indikasi adanya sumber antropogenik, yaitu pencemaran dari aktivitas manusia. Hal ini bisa dilihat pada lokasi KJA yang cenderung lebih tinggi dari daerah lainnya. Fosfat yang tinggi dapat menstimulir pertembuhan fitoplankton, selanjutnya dapat menghambat penetrasi sinar matahari masuk ke perairan sehingga tidak menguntungkan bagi ekosistem perairan. Selain itu waduk juga berfungsi sebagai sumber air minum, dan ambang batas total adalah tidak boleh lebih $50 \mu \mathrm{g} / \mathrm{L}$.

b. Berdasarkan kandungan nitrogen Kandungan nitrogen berkisar $48-1.387 \mu \mathrm{g} / \mathrm{L}$ dengan rata-rata $410 \mu \mathrm{g} / \mathrm{L}$. Berdasarkan nilai

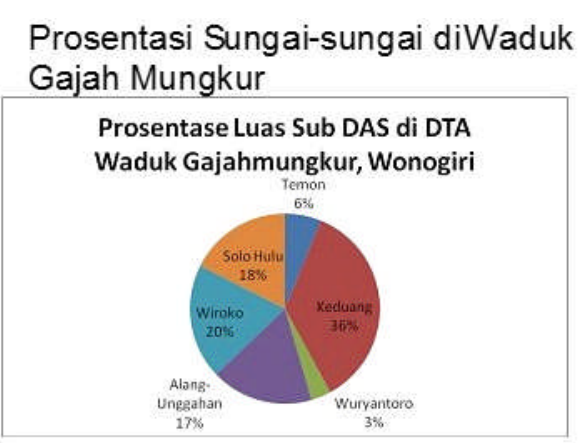

Prosentasi Sungai-sungai di Waduk Gajah Mungkur

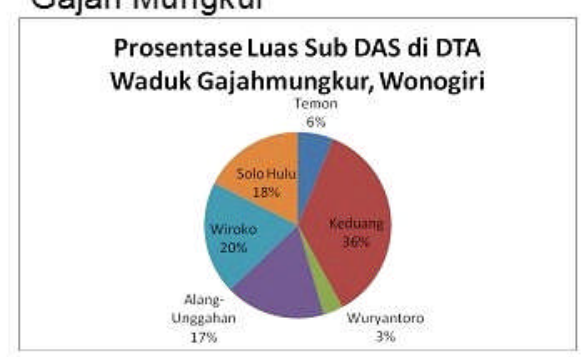

kandungan nitrogen waduk ini termasuk dalam peraira mesotrofik (kesuburan sedang). Nitrogen yang berlebihan menimbulkan pencemaran, kandungan nitrogen yang tinggi dapat disebabkan karena limbah organic.

c. Berdasarkan kandungan klorafil-a

Kandungan total klorofil-adi perairan berkisar 3,57 $-83,3 \mu \mathrm{g} / \mathrm{L}$ dengan rata-rata 21,31 $\mu \mathrm{g} / \mathrm{L}$. Menurut kandungan klorofil-a perairan ini termasuk dalam eutrofik (kesuburan tinggi). Hal ini disebabkan karena jumlah fitoplankton cukup tinggi terutama di daerah KJA.

d. Berdasarkan nilai tropical index (Trix)

Berdasarkan nilai DO saturasi, total-N, total-P dan klorofil-a, diperoleh model TRIX 5,2. Dalam hal ini Waduk Gajah Mungkur sudah termasuk perairan yang eutrop (kesuburan tinggi).

Tingkat sedimentasi bulanan

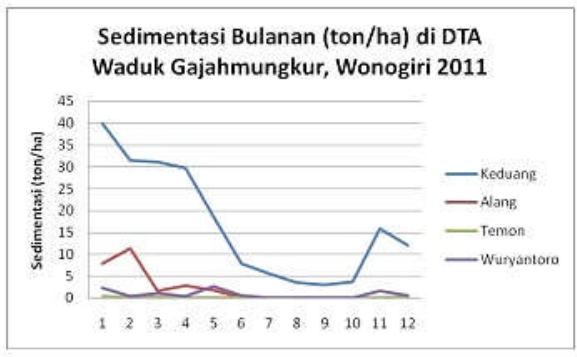

\section{Tingkat sedimentasi bulanan}

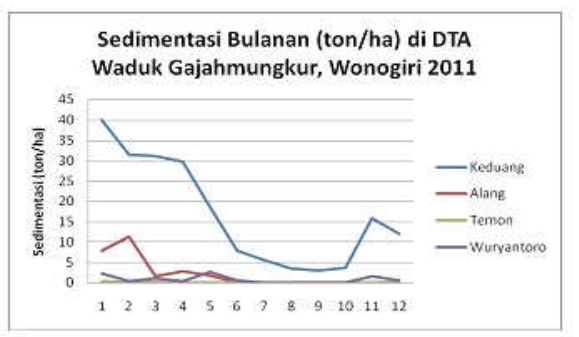

Gambar 3. Sungai-sungai dan tingkat sedimentasi yang masuk di Waduk Gajah Mungkur.

\section{Habitat}

Tingkat sedimentasi yang sangat tinggi karena adanya Daerah Aliran Sungai yang menyebabkan semakin kecilnya daya tampung air. Dari aliran sungai yang menyumbang terbesar sedimentasi adalah Sungai Keduang diantara sungai-sungai lain.

- Sedimentasi ini merupakan proses lanjutan dari erosi yang masuk ke sungai. Sedimentasi yang masuk ke sungai akan terendapkan di waduk dan atau laut. Berdasarkan pengukuran sedimen sepanjang tahun 2011 maka tingkat sedimentasi yang paling besar di DTA Waduk Gajahmungkur adalah yang berasal dari Sub DAS Keduang. Sub DAS yang lain cukup rendah bila dibandingkan dengan sedimentasi sub DAS Keduang. Sedimentasi di DAS Keduang selama tahun 2011 adalah 202.77 ton/ha/th., sedangkan sedimentasi sub DAS Alang, Temon, dan Wuryantoro berturutturut adalah 25,61 ton/ha/th, 0,99 ton/ha/ th, dan 9,17 ton/ha/th.

- Sumber utama pencemaran adalah limbah dari budidaya ikan (KJA) dan limbah rumah tangga.

\section{Jenis ikan di Waduk Gajah Mungkur}

Jenis-jenis ikan di Waduk Gajah Mungkur, dapat dijelaskan ciri dan habitat masing jenis-jenis ikan di Waduk Gajah Mungkur sebagai berikut: 
Tabel 4. Jenis Ikan dan Habitatnya di Waduk Gajah Mungkur

\begin{tabular}{|c|c|}
\hline Jenis Ikan & Habitat \\
\hline Baung & $\begin{array}{l}\text { Mencari makan pada malam hari; suka bersembunyi di dalam liang -liang di tepi sungai } \\
\text { tempat habitat hidupnya; Pakan baung antara lain ikan -ikan kecil, udang -udang kecil, } \\
\text { remis, insekta, molusca, dan rumput; Pertumbuhan ikan baung di alam tergantung } \\
\text { dengan kondisi air, terutama ketinggian dan musim; Pada musim hujan dan air tinggi, } \\
\text { ikan baung tumbuh relative cepat yaitu bulan November -februari. Sedangkan pada } \\
\text { musim kemarau, pertumbuhan ikan baung menurun; Di Waduk Gajah Mungkur, ikan } \\
\text { baung menyebar diseluruh badan waduk. }\end{array}$ \\
\hline Keting & $\begin{array}{l}\text { Hidup di dasar air, omnivora, melimpah musim hujan, siang dan malam sama } \\
\text { dominannya. Melimpah di sungai yang banjir dan muara saat penghujan. Ikan keting } \\
\text { merupakan jenis ikan pemakan detritus, serangga air dan moluska. Selain di Waduk } \\
\text { Gajah Mungkur, juga hidup didaerah rawa banjiran dataran rendah. Sebaran habitat di } \\
\text { Waduk Gajah Mungkur adalah di bagian tepi waduk. }\end{array}$ \\
\hline Kutuk & $\begin{array}{l}\text { Ikan kutuk biasa didapati di danau, rawa, sungai, dan saluran -saluran air hingga ke } \\
\text { sawah-sawah. Ikan ini memangsa aneka ikan kecilkecil, serangga, dan berbagai hewan } \\
\text { air lain termasuk berudu dan kodok. Pada musim kawi n, ikan jantan dan betina } \\
\text { bekerjasama menyiapkan sarang di antara tumbuhan dekat tepi air yang berlumpur. }\end{array}$ \\
\hline Betutu & $\begin{array}{l}\text { Habitat betutu adalah tempat yang arusnya tenang dan agak berlumpur seperti rawa, } \\
\text { danau, atau muara sungai pada kedalaman kira - kira } 40 \text { c m. Ikan ini gemar sekali } \\
\text { membenamkan dirinya di dalam lumpur. ikan ini suka hidup di perairan yang banyak } \\
\text { tanaman airseperti enceng gondok, kayu api, kangkung dan hidrilla. Ikan dewasa } \\
\text { biasanya memangsa ikan lain, udangdan serangga air. Sementara juvenilnøy yang masih } \\
\text { muda memakan kutu air, jentik- jentik serangga, dan stadia larva, betutu juga memakan } \\
\text { plankton nabati (ganggang) dan plankton hewani berukuran renik. }\end{array}$ \\
\hline Patin & $\begin{array}{l}\text { Di Waduk Gajah Mungkur ikan ini memakan ikan, cacing, pellet, serasah dan biji -bijian. } \\
\text { Dialam, pemijahan terjadi pada awal musim hujan hingga bulan januari. Rerumputan } \\
\text { perdu sejenis kayu duri yang banyak berada di inlet waduk mempunyai peran penting } \\
\text { untuk tempat pemijahan ikan pada musim hujan. Anak-anak patin hidup bergerombol di } \\
\text { bawah kayu duri, didaerah teluk. Induk patin yang akan memijah bermigrasi ke sungai } \\
\text { keduang. Tempat pemijahan biasanya dirumpon (kayu berduri) yang berada di inlet } \\
\text { waduk. }\end{array}$ \\
\hline Nila & $\begin{array}{l}\text { Ikan nila cepat tumbuh bila perairannya banyak tumbuhan lunak seperti hydrilla, } \\
\text { ganggang, plankton. Secara alami ikan nila memijah setelah turun hujan. Ikan jantan } \\
\text { membuat sarang berbentuk cekungan didasar perairan dengan diameter } 30 \quad-50 \mathrm{~cm} \\
\text { sesuai dengan besarnya ikan. Pembuahan terjadi didasar cekungan tersebut. Ikan nila } \\
\text { menyebar diseluruh badan air Waduk Gajah Mungkur. }\end{array}$ \\
\hline Lele & $\begin{array}{l}\text { Lele termasuk ikan omnivore yang lebih condong ke karnivora. Aktif makan pada malam } \\
\text { hari, dengan jenis makanan cacing, ikan kecil, serangga maolusca dan detritus. Senang } \\
\text { hidup diperairan yang dangkal. Reproduksi lele dimulai pada awal musim penghujan. } \\
\text { Merupakan ikan penghuni rawa. Distribusi ikan lele di Waduk Gajah Mungkur berada di } \\
\text { tepi waduk dan daerah inlet. }\end{array}$ \\
\hline Sili & $\begin{array}{l}\text { Merupakan ikan predator yang memangsa anak -anak ikan dan ikan kecil. Pemijahan } \\
\text { bersifat eksternal dan telur menyebar di badan badan air. Ikan sili merupakan ikan dasar, } \\
\text { hidup diair tawar dan estuarine. Distribusi di Waduk gajah mungkuar berada di dasar } \\
\text { perairan badan air sungai masuk (inlet) seperti sungai keduang. }\end{array}$ \\
\hline Gurami & $\begin{array}{l}\text { Pada waktu memijah, telur gurami dilekatkan di tumbuhan air atau ditaruh disarang yang } \\
\text { terbuat dari tumbuh-tumbuhan. Makanan utama gurami adalah tumbuhan, namun juga } \\
\text { pemangsa serangga, ikan lain, dan juga barang yang membusuk diair. Di alam, gurami } \\
\text { hidup di sungai, rawa dan kolam . Menyukai perairan yang dangkal yang banyak } \\
\text { tumbuhan. Di gajah mungkur, banyak berada di daerah tepi waduk yang banyak terdapat } \\
\text { tumbuhan air. }\end{array}$ \\
\hline Mujair & $\begin{array}{l}\text { Makanannya terdiri dari alga dan tumbuh tumbuhan. Mudah berkembang biak dalam } \\
\text { segala perairan. Dikenal dengan mouth breeder (pengeraman telur dalam mulut), karena } \\
\text { induk betina mengulum telur yang telah dibuahi didalam rongga mulutnya yang berfun\$i } \\
\text { sebagai incubator. Di Waduk Gajah Mungkur, penyebarannya tersebar diseluruh badan } \\
\text { air waduk. }\end{array}$ \\
\hline Tawes & $\begin{array}{l}\text { Kebiasaan makan bersifat herbivore. Makanan utamanya adalah tumbuhan air, detritus, } \\
\text { fitoplankton. Tumbuhan air meliputi gulma air, enceng gondok, rerumputan ditepian } \\
\text { perairan, dan kiambang. Diperairan umum memijah pada musim penghujan. Telur } \\
\text { mengendap pada dasar perairan. Di Waduk Gajah Mungkur, ikan tawes hidup tersebar } \\
\text { diseluruh perairan. }\end{array}$ \\
\hline
\end{tabular}


Dari Tabel tersebut diatas, sebagian besar ikan yang berada di Waduk Gajah Mungkur mempunyai habitat di dasar perairan yang banyak ditumbuhi tanaman air maupun tanaman berduri. Memijah umumnya pada musim penghujan di daerah inlet atau teluk. Dari habitat jenis-jenis ikan tersebut diatas, maka dapat dijelaskan tingkah laku, pola makan dan habitat jenis ikan di Waduk Gajah Mungkur sebagai berikut:

\begin{tabular}{|c|c|c|c|c|}
\hline No & Ikan & Makanan & Tempat Hidup & Lapisan Renang \\
\hline 1. & Baung & Ikan kecil, serangga & Liang-liang, lubang-lubang & Dasar perairan \\
\hline 2. & Gabus & Ikan kecil, serangga & Tumbuhan air, lumpur & Dasar perairan \\
\hline 3. & Betutu & Ikan kecil, serangga & Lumpur, terlindung & Dasar perairan \\
\hline 4. & Patin & Ikan, udang, serasah & Kayu berduri, rumput & $\begin{array}{l}\text { Pertengahan- } \\
\text { permukaan }\end{array}$ \\
\hline 5. & Nila & $\begin{array}{l}\text { Hidrilla, ganggang, } \\
\text { plankton }\end{array}$ & $\begin{array}{l}\text { Sekitar tumbuhan } \\
\text { lunak }\end{array}$ & $\begin{array}{l}\text { Dasar-pertengahan- } \\
\text { permukaan }\end{array}$ \\
\hline 6. & lele & Cacing, ikan kecil & Perairan dangkal & Dasar-pertegahan \\
\hline 7. & Sili & Ikan kecil & Inlet sungai & Dasar perairan \\
\hline 8. & $\begin{array}{l}\text { Guram } \\
\text { e }\end{array}$ & Tumbuhan, serangga & $\begin{array}{l}\text { Perairan dangkal, } \\
\text { banyak tumbuhan }\end{array}$ & $\begin{array}{l}\text { Dasar, Pertengahan, } \\
\text { permukaan }\end{array}$ \\
\hline 9. & Mujair & $\begin{array}{l}\text { Tumbuhan, } \\
\text { ganggang, cacing }\end{array}$ & $\begin{array}{l}\text { Sekitar tumbuhan } \\
\text { lunak }\end{array}$ & $\begin{array}{l}\text { Dasar-pertengahan- } \\
\text { permukaan }\end{array}$ \\
\hline 10. & Tawes & Tumbuhan air & rerumputan & $\begin{array}{l}\text { Dasar perairan } \\
\text { pertengahan }\end{array}$ \\
\hline
\end{tabular}

\section{Hasil}

Artifisial Habitat yang ditenggelamkan baik type I, II dan III, telah dihuni oleh beberapa jenis ikan antara lain Nila (dominan);Lukas, Tawes dengan beberapa ukuran $(5-30 \mathrm{Cm})$ dan berat $(10-325 \mathrm{gram})$, rata rata tiap unit artifisial ditempati 1 sampai dengan 5 ekor ikan. Atraktor genteng merupakan jenis atraktor yang paling diminati sebagai tempat menempelnya telur ikan, sedangkan jenis atraktor lain saat monitoring tidak ditemui ada telur yang menempel. Dinas Peternakan Perikanan dan Kelautan setempat sangat mendukungterhadap kegiatan survai lapangan yang akan dilaksanakan oleh Tim BPPI Semarang, bahkan instansi/lembaga lainnya yang terkait juga siap mendukung dan membantu untuk kemudahan serta kelancarannya.

\section{KESIMPULAN}

Artifisial Habitat di Waduk Gajah Mungkur efektif, berfungsi sebagai tempat meletakkan telur telur ikan dan pengasuhan anakan ikan.

\section{PERSANTUNAN}

Terimakasih kepada kepala BPPI, Semarang yang telah memberikan ijin untuk penulisan makalah tentang penenggelaman Artificial Habita di Waduk Gadjah Mungkur.

\section{DAFTAR PUSTAKA}

Anderson, LG. (1986). The Economic of Fisheries Management (p. 296). The John Hopkins University Press, Baltimore.

Agus, P \& Salim, S. (1996 \& 1997). Informasi Sumberdaya Ikan Demersal di Kalimantan Bagian Proyek Pengembangan Teknologi Penangkapan Ikan. BPPI, Semarang, $61 \mathrm{hlm}$.

Agus, P., Salim, S., \& Soewito. (1998). Pemakaian Artifisial Habitat untuk Mendukung Keberhasilan Operasi Rawai Dasar. Balai Pengembangan Penangkapan lkan, Semarang.

Anonimus (1987). Penyebaran Beberapa Sumber Perikanan di Indonesia. Direktorat Bina Sumber Hayati Direktorat Jenderal Perikanan Departemen Pertanian, Jakarta, $43 \mathrm{hlm}$.

Anonimus (1990). Buku Pedoman Pengenalan Sumber Perikanan Laut (Jenis-jenis Ikan Ekonomis Penting). Direktorat Perikanan Departemen Pertanian, Jakarta, $170 \mathrm{hlm}$.

Mulyono. (1986). Alat-alat Penangkapan Ikan Buku III: Macam-Macam Pancing, Perangkap, dan Jaring Angkat. Dinas Perikanan Propinsi Dati I Jawa Tengah, Semarang, $264 \mathrm{hlm}$. 